\title{
The predictive value of arterial stiffness on major adverse cardiovascular events in individuals with mildly impaired renal function
}

This article was published in the following Dove Press journal:

Clinical Interventions in Aging

29 August 2016

Number of times this article has been viewed

\author{
Jie Han* \\ Xiaona Wang* \\ Ping Ye \\ Ruihua Cao \\ Xu Yang \\ Wenkai Xiao \\ Yun Zhang \\ Yongyi Bai \\ Hongmei Wu \\ Department of Geriatric Cardiology, \\ Chinese PLA General Hospital, \\ Beijing, People's Republic of China \\ *These authors contributed equally \\ to this work
}

Objectives: Despite growing evidence that arterial stiffness has important predictive value for cardiovascular disease in patients with advanced stages of chronic kidney disease, the predictive significance of arterial stiffness in individuals with mildly impaired renal function has not been established. The aim of this study was to evaluate the predictive value of arterial stiffness on cardiovascular disease in this specific population.

Materials and methods: We analyzed measurements of arterial stiffness (carotid-femoral pulse-wave velocity [cf-PWV]) and the incidence of major adverse cardiovascular events (MACEs) in 1,499 subjects from a 4.8-year longitudinal study.

Results: A multivariate Cox proportional-hazard regression analysis showed that in individuals with normal renal function (estimated glomerular filtration rate [eGFR] $\geq 90 \mathrm{~mL} / \mathrm{min} / 1.73 \mathrm{~m}^{2}$ ), the baseline cf-PWV was not associated with occurrence of MACEs (hazard ratio 1.398, $95 \%$ confidence interval $0.748-2.613 ; P=0.293$ ). In individuals with mildly impaired renal function (eGFR $<90 \mathrm{~mL} / \mathrm{min} / 1.73 \mathrm{~m}^{2}$ ), a higher baseline cf-PWV level was associated with a higher risk of MACEs (hazard ratio 2.334, 95\% confidence interval 1.082-5.036; $P=0.031$ ).

Conclusion: Arterial stiffness is a moderate and independent predictive factor for MACEs in individuals with mildly impaired renal function (eGFR $<90 \mathrm{~mL} / \mathrm{min} / 1.73 \mathrm{~m}^{2}$ ).

Keywords: epidemiology, arterial stiffness, impaired renal function, predictive value, MACEs

\section{Introduction}

In recent years, there has been greater interest in the role of arterial stiffness in the development of cardiovascular disease (CVD). Several patient- and populationbased cohort studies have proved a strong relationship between augmented arterial stiffness and increased risk of CVD, such as stroke, myocardial infarction, and heart failure. ${ }^{1-5}$ By means of pulse-wave velocity (PWV) measurement, arterial stiffness can be assessed noninvasively. With a large amount of epidemiological evidence, the velocity of carotid-femoral PWV (cf-PWV) seems to be very important in prognosis, requires little technical expertise, and is considered to be the gold standard for assessing central arterial stiffness..$^{5-7}$

CVD is one of the leading causes of morbidity and mortality in patients with chronic kidney disease (CKD). Patients with CKD are more likely to die from CVD than progress to end-stage renal disease (ESRD), let alone patients who have already progressed to ESRD or dialysis. ${ }^{8}$ In addition to traditional CV risk factors, including advanced age, diabetes, hypertension, dyslipidemia, and smoking, largevessel arterial stiffness, which is a common issue in CKD, is considered another 
newfound mechanism accounting for the increased risk of CVD in CKD. ${ }^{9}$ Several studies have demonstrated that increased arterial stiffness is a strong and independent predictor of mainly $\mathrm{CV}$ and all-cause mortality in patients with ESRD. ${ }^{10-13}$ These population-specific studies focused much of their attention on advanced stages of CKD. However, after adjusting for other traditional CV risk factors, even mild impairment of renal function (estimated glomerular filtration rate $[\mathrm{eGFR}]<90 \mathrm{~mL} / \mathrm{min} / 1.73 \mathrm{~m}^{2}$ ) becomes an independent $\mathrm{CV}$ risk factor. ${ }^{14}$ Therefore, a new problem arises: Is arterial stiffness predictive in individuals with mild renal impairment?

We hypothesize that arterial stiffness is an independent predictive factor of CVD, which is replaced by major adverse $\mathrm{CV}$ events (MACEs) as major end points in individuals with mildly impaired renal function. Therefore, the present study investigated the predictive value of arterial stiffness (cf-PWV) on CVD (MACEs) by studying the association between levels of cf-PWV at baseline and the incidence of MACEs during the follow-up period in a large, communitybased, longitudinal sample grouped by renal function (eGFR) from Beijing, People's Republic of China.

\section{Materials and methods Study population}

This community-based cohort study was carried out in the Pingguoyuan area of Shijingshan district, Beijing, People's Republic of China. Subjects with severe systemic diseases, including severe liver, renal, endocrine, metabolic (except for diabetes mellitus, DM), and neoplastic diseases, collagenosis, inflammation, heart failure, and a history of ischemic heart disease were excluded. In total, 1,680 participants (age $\geq 18$ years) were initially eligible for the study after a routine health checkup between September 2007 and January 2009.

This community-based population was followed prospectively, and the second visit for these participants was conducted from February 1 to September 30, 2013. During the second visit, all participants came to the community medical center and received a questionnaire survey. The median follow-up was 4.8 years. During this period, 181 participants were excluded from the study on account of failure to follow-up. Finally, integrated data were obtained from 1,499 participants, and the rate of follow-up was $89.2 \%$. The study protocol was approved by the Ethics Committee of the People's Liberation Army (PLA) General Hospital (Beijing, People's Republic of China), and each participant provided informed written consent.

\section{Questionnaire and anthropometric measurements}

Information that included lifestyle factors, prevalent diseases, family history, and medication use was collected with standardized self-reporting questionnaires, which were carried out by a face-to-face counseling method. Trained physicians from the Department of Geriatric Cardiology at the PLA General Hospital completed this investigation. Height and weight were measured by a wall-mounted measuring tape and a digital scale, respectively. Systolic blood pressure (SBP) and diastolic BP (DBP) were measured on the right arm twice in a sitting position after 5 minutes of rest. The average measurements of SBP and DBP were calculated for further analysis.

\section{Biomarker-variable determination}

Blood samples of participants were collected from 8 am to $10 \mathrm{am}$ after 12 hours of fasting. These samples were preserved at $4^{\circ} \mathrm{C}$ for 2 hours at most, before being centrifuged at $1,200 \mathrm{~g}$ for 15 minutes. Before the assays were performed, plasma aliquots were frozen at $-80^{\circ} \mathrm{C}$. Concentrations of fasting blood glucose, triglyceride, total cholesterol, highdensity lipoprotein cholesterol, and low-density lipoprotein cholesterol were detected by using Roche enzymatic assays (Roche Diagnostics GmbH, Mannheim, Germany) on a Roche autoanalyzer. Concentrations of plasma creatinine were detected by using an enzymatic assay (Roche) on a Hitachi 7600 autoanalyzer (Hitachi, Tokyo, Japan). All blood samples were analyzed in the same laboratory, following the criteria of the World Health Organization lipid reference laboratories.

\section{Assessment of arterial stiffness}

Measurement of arterial stiffness was conducted in a quiet environment in the morning at a stable temperature. All participants were asked to avoid alcohol, smoking, and caffeine for at least 12 hours before measurement. After resting in the supine position for 5 minutes, arterial stiffness was measured by automatic cf-PWV measurement using a Complior SP device (Créatech SAS, Besançon, France), which achieves online recording of PW and automatic calculating of PWV. Two TY-306 Fukuda pressure-sensitive transducers (Fukuda Denshi Co Ltd, Tokyo, Japan) were used: one transducer over the common carotid artery at the bottom of the neck, and the other transducer over the femoral artery. We collected PWs of both the carotid artery and the femoral artery simultaneously at two different sites, and repeated at least 
ten independent and complete cardiac cycles. The average value was calculated for the final analysis. PWV was calculated from the measurement of the pulse-transit time and the distance traveled by the pulse between the two recording sites (measured on the surface of the body in meters), and on the basis of the formula:

$$
\operatorname{cf-PWV}(\mathrm{m} / \mathrm{s})=\frac{\text { Distance }(\mathrm{m})}{\text { Transit time }(\mathrm{s})}
$$

\section{Definition of variables}

Hypertension was defined as 1) SBP $\geq 140 \mathrm{mmHg}$, 2) $\mathrm{DBP} \geq 90 \mathrm{mmHg}$, and/or 3 ) the use of antihypertensive medication. Smoking status was defined as smoking one or more cigarettes per day for at least 1 year. Body mass index was defined as weight in kilograms divided by height in meters squared $\left(\mathrm{kg} / \mathrm{m}^{2}\right)$. Renal function was evaluated by eGFR. eGFR was calculated using the following Chronic Kidney Disease Epidemiology Collaboration equation:

$$
\begin{aligned}
\operatorname{GFR}= & 141 \times \min (\operatorname{Scr} / \kappa, 1)^{\alpha} \times \max (\operatorname{Scr} / \kappa, 1)^{-1.209} \\
& \times 0.993^{\text {Age }} \times 1.018(\text { if female }) \times 1.159(\text { if black })
\end{aligned}
$$

where Scr is plasma creatinine $(\mathrm{mg} / \mathrm{dL}), \kappa$ is 0.7 for females and 0.9 for males, $\alpha$ is -0.329 for females and -0.411 for males, min indicates the minimum of $\mathrm{Scr} / \kappa$ or 1 , and $\max$ indicates the maximum of $\mathrm{Scr} / \kappa$ or 1 .

\section{End points}

The major end points assessed were MACEs. In our study, MACEs included cardiocerebrovascular death (including both $\mathrm{CV}$ death and cerebrovascular death), nonfatal myocardial infarction, and stroke (including both ischemic and hemorrhagic stroke). Death was ascertained from legal death records. ${ }^{15}$

\section{Statistical analyses}

Results are expressed as numbers and percentages for dichotomous variables and mean \pm standard deviation or median (interquartile range) for continuous variables. The continuous variables were tested for normality before being tested, and were normalized by natural logarithm transformation as necessary. All analyses were performed at a median follow-up interval of 4.8 years.

We chose $90 \mathrm{~mL} / \mathrm{min} / 1.73 \mathrm{~m}^{2}$ as a cutoff point for eGFR, and $30 \mathrm{~mL} / \mathrm{min} / 1.73 \mathrm{~m}^{2}$ as a lower cutoff point for renal function, in order to exclude severe renal dysfunctions. In our study population, subjects with severe liver and renal diseases had already been excluded at the very beginning, and thus the renal function of all participants was above the lower cutoff point. Participants were classified into two groups: a normal renal function group and an impaired renal function group. Then, we chose $12 \mathrm{~m} / \mathrm{s}$ as a cutoff point for cf-PWV, in accordance with the upper third of cf-PWV reported by Blacher et al. ${ }^{11} \mathrm{cf}-\mathrm{PWV} \geq 12 \mathrm{~m} / \mathrm{s}$ is considered elevated and $<12 \mathrm{~m} / \mathrm{s}$ is considered normal. Finally, according to eGFR and cf-PWV levels, participants were classified into four groups: group 1 (eGFR $\geq 90 \mathrm{~mL} / \mathrm{min} / 1.73 \mathrm{~m}^{2}$, cf$\mathrm{PWV}<12 \mathrm{~m} / \mathrm{s} ; \mathrm{n}=744)$, group 2 (eGFR $\geq 90 \mathrm{~mL} / \mathrm{min} / 1.73 \mathrm{~m}^{2}$, cf-PWV $\geq 12 \mathrm{~m} / \mathrm{s} ; \mathrm{n}=230)$, group $3\left(\mathrm{eGFR}<90 \mathrm{~mL} / \mathrm{min} / 1.73 \mathrm{~m}^{2}\right.$, cf-PWV $<12 \mathrm{~m} / \mathrm{s} ; \mathrm{n}=256)$, and group 4 (eGFR $<90 \mathrm{~mL} / \mathrm{min} / 1.73 \mathrm{~m}^{2}$, cf-PWV $\geq 12 \mathrm{~m} / \mathrm{s} ; \mathrm{n}=242$ ). Statistical comparison of these groups was analyzed by Student's $t$-test (continuous variables) or $\chi^{2}$ test (dichotomous variables).

A multivariate Cox proportional-hazard regression model was used to calculate hazard ratios (HRs) and 95\% confidence intervals (CIs) to estimate the relative risks of the incidence of MACEs. Regression models were adjusted for age and sex as independent variables (model 1), and additionally adjusted for body mass index, SBP, DBP, fasting blood glucose, triglyceride, total cholesterol, high-density lipoprotein cholesterol, and low-density lipoprotein cholesterol as independent variables (model 2). All analyses were conducted using SPSS software for Windows, version 13.0 (SPSS, Chicago, IL, USA). $P$-values $<0.05$ were considered statistically significant.

\section{Results \\ Baseline clinical characteristics of participants}

A total of 1,499 participants were included in the analysis. There were 630 males (42\%) and 869 females (58\%). The baseline mean age was 61.4 years. There were 99 participants who had MACEs during the 4.8-year follow-up. The distribution of the different MACEs in each group is shown in Table 1. Demographic characteristics, CV risk factors, and related laboratory test results in each group are also shown in Table 1.

\section{Association of baseline cf-PWV and eGFR levels with MACEs}

In normal renal function groups, the incidence of MACEs significantly increased from $2.69 \%$ in group 1 to $9.57 \%$ in 
Table I Baseline characteristics of subjects according to renal function and arterial stiffness

\begin{tabular}{|c|c|c|c|c|c|}
\hline \multirow[t]{3}{*}{ Variable } & \multicolumn{2}{|c|}{ eGFR $\geq 90\left(\mathrm{~mL} / \mathrm{min} / \mathrm{I} .73 \mathrm{~m}^{2}\right)$} & \multicolumn{2}{|c|}{ eGFR $<90\left(\mathrm{~mL} / \mathrm{min} / \mathrm{I} .73 \mathrm{~m}^{2}\right)$} & \multirow[t]{3}{*}{$P$-value } \\
\hline & cf-PWV < I2 (m/s) & cf-PWV $\geq 12(\mathrm{~m} / \mathrm{s})$ & cf-PWV < I2 (m/s) & cf-PWV $\geq 12(\mathrm{~m} / \mathrm{s})$ & \\
\hline & Group I $(n=744)$ & Group $2(n=230)$ & Group $3(n=256)$ & Group $4(n=242)$ & \\
\hline Age (years) & $51.66 \pm 7.436$ & $59.31 \pm 8.193$ & $61.49 \pm 10.346$ & $69.62 \pm 6.869$ & $<0.001$ \\
\hline Women, n (\%) & $497(66.8)$ & $124(53.91)$ & $127(49.6)$ & $|2|(50)$ & $<0.00$ I \\
\hline BMI $\left(\mathrm{kg} / \mathrm{m}^{2}\right)$ & $25.436 \pm 3.311$ & $25.436 \pm 3.35$ & $25.553 \pm 3.544$ & $25.391 \pm 3.167$ & 0.924 \\
\hline $\mathrm{SBP}(\mathrm{mmHg})$ & $123.62 \pm 15.928$ & $|32.7 \pm| 5.47 \mid$ & $128.09 \pm \mid 7.318$ & $137.55 \pm 18.117$ & $<0.00 \mathrm{I}$ \\
\hline $\mathrm{DBP}(\mathrm{mmHg})$ & $77.58 \pm 10.016$ & $78.64 \pm 9.059$ & $76.9 \pm 10.102$ & $75.82 \pm 10.621$ & 0.026 \\
\hline $\mathrm{TC}(\mathrm{mmol} / \mathrm{L})$ & $4.982 \pm 0.9$ & $4.973 \pm 0.906$ & $5.094 \pm 0.842$ & $5.059 \pm 0.931$ & 0.237 \\
\hline TG (mmol/L) & $1.773 \pm 0.215$ & $1.938 \pm 0.283$ & $1.722 \pm 0.183$ & $1.903 \pm 0.327$ & 0.105 \\
\hline $\mathrm{HDL}-\mathrm{C}(\mathrm{mmol} / \mathrm{L})$ & $1.417 \pm 0.357$ & $1.34 \pm 0.378$ & $1.408 \pm 0.372$ & $1.328 \pm 0.348$ & 0.001 \\
\hline LDL-C (mmol/L) & $2.86 \pm 0.715$ & $2.907 \pm 0.716$ & $2.926 \pm 0.674$ & $3.01 \pm 0.746$ & 0.025 \\
\hline FBG (mmol/L) & $5.40 \mathrm{I} \pm \mathrm{I} .706$ & $5.856 \pm 1.164$ & $5.138 \pm 1.116$ & $5.502 \pm 1.75 \mid$ & $<0.001$ \\
\hline eGFR $\left(\mathrm{mL} / \mathrm{min} / \mathrm{l} .73 \mathrm{~m}^{2}\right)$ & $105.201 \pm 5.924$ & $102.848 \pm 5.572$ & $84.11 \pm 10.511$ & $81.876 \pm 11.697$ & $<0.00$ I \\
\hline cf-PWV (m/s) & $9.567 \pm 1.27 \mid$ & $|3.3| \pm \mid .204$ & $9.921 \pm 1.503$ & $14.739 \pm 2.739$ & $<0.001$ \\
\hline MACEs, n (\%) & $20(2.69)$ & $22(9.57)$ & $21(8.2)$ & $36(14.88)$ & $<0.001$ \\
\hline Cardiocerebrovascular death, n (\%) & $2(0.269)$ & $3(1.304)$ & $7(2.734)$ & $13(5.372)$ & $<0.001$ \\
\hline New-onset myocardial infarction, n (\%) & $3(0.403)$ & $3(1.304)$ & I (0.39) & $4(1.653)$ & $<0.001$ \\
\hline New-onset stroke, n (\%) & $15(2.016)$ & $16(6.957)$ & $13(5.078)$ & $19(7.85 \mathrm{I})$ & $<0.00$ I \\
\hline Ischemic stroke & $14(1.882)$ & $13(5.652)$ & II (4.297) & $16(6.612)$ & $<0.001$ \\
\hline Hemorrhagic stroke & I (0.134) & $3(1.304)$ & $2(0.78 I)$ & $3(1.24)$ & $<0.001$ \\
\hline All-cause deaths, $\mathrm{n}(\%)$ & $9(1.21)$ & $10(4.35)$ & $12(4.69)$ & $21(8.68)$ & $<0.001$ \\
\hline
\end{tabular}

Note: Continuous variables expressed as mean \pm standard deviation or median (interquartile range).

Abbreviations: BMI, body mass index; SBP, systolic blood pressure; DBP, diastolic blood pressure; TC, total cholesterol; TG, triglyceride; LDL-C, low-density lipoprotein cholesterol; HDL-C, high-density lipoprotein cholesterol; FBG, fasting blood glucose; eGFR, estimated glomerular filtration rate; cf-PWV, carotid-femoral pulse-wave velocity; MACEs, major adverse cardiovascular events.

group 2. Baseline cf-PWV was associated with the occurrence of MACEs (HR 1.862, 95\% CI 1.054-3.287; $P=0.032$ ) in the unadjusted model, but the association disappeared when the models were additionally adjusted for age, sex, BP, plasma lipids, and other traditional risk factors (HR 1.398, 95\% CI 0.748-2.613; $P=0.293$ ) (model 2 in Table 2). Furthermore, the association remained insignificant after adjustment for stroke (HR 0.453, 95\% CI 0.017-11.867; P=0.635) (model 3 in Table 2).

Table 2 Baseline arterial stiffness and incidence of MACEs over a 4.8-year follow-up in normal renal function

\begin{tabular}{lll}
\hline $\begin{array}{l}\text { Incidence } \\
\text { of MACEs }\end{array}$ & Group 2 vs group I \\
\cline { 2 - 3 } & HR (95\% CI) & P-value \\
\hline Unadjusted & $1.862(1.054-3.287)$ & 0.032 \\
Model I & $1.452(0.80 I-2.634)$ & 0.219 \\
Model 2 & $1.398(0.748-2.613)$ & 0.293 \\
Model 3 & $0.453(0.017-11.867)$ & 0.635 \\
\hline
\end{tabular}

Notes: Data presented as HRs (per SD increase in cf-PWV level) and corresponding $95 \%$ Cls. Normal renal function: eGFR $\geq 90 \mathrm{~mL} / \mathrm{min} / 1.73 \mathrm{~m}^{2}$. In the Cox regression model, MACEs were treated as the dependent variable (MACEs vs non-MACEs). Model I adjusted for age and sex; model 2 adjusted for age, sex, BMI, SBP, DBP, TC, TG, HDL-C, LDL-C, and FBG; model 3 adjusted for age, sex, BMI, SBP, DBP, TC, TG, HDL-C, LDL-C, FBG, and stroke.

Abbreviations: $\mathrm{HR}$, hazard ratio; $\mathrm{Cl}$, confidence interval; SD, standard deviation; BMI, body mass index; SBP, systolic blood pressure; DBP, diastolic blood pressure; TC, total cholesterol; TG, triglyceride; LDL-C, low-density lipoprotein cholesterol; HDL-C, high-density lipoprotein cholesterol; FBG, fasting blood glucose; eGFR, estimated glomerular filtration rate; cf-PWV, carotid-femoral pulse-wave velocity; MACEs, major adverse cardiovascular events.
In the impaired renal function groups, the incidence of MACEs significantly increased from $8.2 \%$ in group 3 to $14.88 \%$ in group 4 . A higher baseline cf-PWV level was associated with a higher risk of MACEs after adjustment for age, sex, BP, plasma lipids, and other traditional risk factors. Although the risk ratio was reduced after adjustment, the participants in group 4 still had a significantly higher risk of MACEs (HR 2.334, 95\% CI 1.082-5.036; $P=0.031$ ) compared to group 3 (model 2 in Table 3). Furthermore,

Table 3 Baseline arterial stiffness and incidence of MACEs over a 4.8-year follow-up in mildly impaired renal function

\begin{tabular}{lll}
\hline $\begin{array}{l}\text { Incidence } \\
\text { of MACEs }\end{array}$ & Group 4 vs group 3 & \\
\cline { 2 - 3 } & HR $(\mathbf{9 5 \%} \mathbf{C I})$ & $\boldsymbol{P}$-value \\
\hline Unadjusted & $4.345(2.307-8.182)$ & $<0.001$ \\
Model I & $2.426(1.204-4.886)$ & 0.013 \\
Model 2 & $2.334(1.082-5.036)$ & 0.031 \\
Model 3 & $2.400(1.106-5.208)$ & 0.027 \\
\hline
\end{tabular}

Notes: Data presented as HRs (per SD increase in cf-PWV level) and corresponding $95 \%$ Cls. Mildly impaired renal function: eGFR $<90 \mathrm{~mL} / \mathrm{min} / 1.73 \mathrm{~m}^{2}$. In the Cox regression model, MACEs were treated as the dependent variable (MACEs vs nonMACEs). Model I adjusted for age and sex; model 2 adjusted for age, sex, BMI, SBP, DBP, TC, TG, HDL-C, LDL-C, and FBG; model 3 adjusted for age, sex, BMI, SBP, DBP, TC, TG, HDL-C, LDL-C, FBG, and stroke.

Abbreviations: $\mathrm{HR}$, hazard ratio; $\mathrm{Cl}$, confidence interval; $\mathrm{SD}$, standard deviation; BMI, body mass index; SBP, systolic blood pressure; DBP, diastolic blood pressure; TC, total cholesterol; TG, triglyceride; LDL-C, low-density lipoprotein cholesterol; HDL-C, high-density lipoprotein cholesterol; FBG, fasting blood glucose; eGFR, estimated glomerular filtration rate; cf-PWV, carotid-femoral pulse-wave velocity; MACEs, major adverse cardiovascular events. 
after adjustment for stroke, the risk ratio was still higher in group 4 (HR 2.4, 95\% CI 1.106-5.208; $P=0.027$ ) (model 3 in Table 3 ).

\section{Discussion}

In the current longitudinal study, we observed that after adjusting for age and sex, as well as other traditional CV risk factors, $c f-P W V \geq 12 \mathrm{~m} / \mathrm{s}$ had a higher predictive value on MACEs in individuals with eGFR $<90 \mathrm{~mL} / \mathrm{min} / 1.73 \mathrm{~m}^{2}$, compared with cf-PWV $<12 \mathrm{~m} / \mathrm{s}$. Furthermore, we also found that the risk of MACEs did not increase with incremental cf-PWV, according to adjusted models in individuals with eGFR $\geq 90 \mathrm{~mL} / \mathrm{min} / 1.73 \mathrm{~m}^{2}$.

PWV measurement offers a simple and noninvasive assessment of regional arterial stiffness. Intermittent ventricular ejection can lead to oscillatory changes in BP, and a very important function of the aorta and large arteries is to buffer these changes. The high distensibility of the arterial system helps most tissues avoid peak systolic pressures and receive near-steady flow. Impairment of distensibility makes the aorta and large arteries become rigid and unable to buffer the oscillatory changes caused by intermittent ventricular ejection, which results in elevated systolic pressure. Therefore, important organs, including the heart, brain, and kidneys, suffer greatly from higher systolic pressures and greater-pressure oscillatory changes as arterial stiffness increases, leading to myocardial hypertrophy and fibrosis, renal impairment, microvascular damage, and an increased risk of MACEs. ${ }^{16-19}$ Taken together, PWV measurements are fit for large-scale studies, and several studies ${ }^{20-22}$ have already demonstrated the predictive ability of arterial stiffness on the risk of MACEs.

However, many new questions appear as more results become available. One of these concerns the fact that although a common conception based on the results of individual studies proved that arterial stiffness has an important predictive role, these studies involved different populations. We would like to know more clearly whether arterial stiffness exerts a different predictive ability in populations with different characteristics and estimated baseline $\mathrm{CV}$ risks. $^{23}$

A meta-analysis of 17 longitudinal studies performed by Vlachopoulos et al found that arterial stiffness offered higher predictive ability in individuals with a higher baseline $\mathrm{CV}$ risk. ${ }^{23}$ Among all the $\mathrm{CV}$ risk factors, as previous studies have shown, CKD leads to an elevated risk of $\mathrm{CV}$, with an inverse graded relationship with eGFR $<60 \mathrm{~mL} / \mathrm{min} / 1.73 \mathrm{~m}^{2}$, independently of other traditional $\mathrm{CV}$ risk factors. ${ }^{24-26}$
However, most attention has been focused on the predictive ability of arterial stiffness in patients with ESRD or even requiring dialysis. ${ }^{27-29}$

Moreover, current guidelines accept eGFR $<60 \mathrm{~mL} /$ $\min / 1.73 \mathrm{~m}^{2}$ as a cutoff point for an increased risk of CKD complications. Individuals with eGFR between 60 and $89 \mathrm{~mL} / \mathrm{min} / 1.73 \mathrm{~m}^{2}$ are not considered to have CKD unless there is also a marker of renal impairment, eg, proteinuria. ${ }^{24-26}$ Therefore, the key issue we investigated in the current work was whether arterial stiffness is predictive in individuals with mildly impaired renal function.

In our present community-based cohort study, we chose $90 \mathrm{~mL} / \mathrm{min} / 1.73 \mathrm{~m}^{2}$ as the cutoff point for eGFR, and found that $\mathrm{cf}-\mathrm{PWV} \geq 12 \mathrm{~m} / \mathrm{s}$ was a moderate predictor of MACEs in individuals with eGFR $<90 \mathrm{~mL} / \mathrm{min} / 1.73 \mathrm{~m}^{2}$ (HR 2.334, 95\% CI 1.082-5.036; $P=0.031)$. This result suggests that arterial stiffness is predictive even in individuals with mildly impaired renal function, and not just in individuals with ESRD or on dialysis. This predictive ability remains after adjustment for other established traditional CV risk factors.

Understanding the association between increased arterial stiffness, mild renal impairment, and the risk of MACEs is vital to guide preventive strategies for screening and treatment. ${ }^{14}$ Although CV risk in ESRD is extreme, the public health burden of CV disease caused by early stage CKD is much greater. ${ }^{30-32}$ Improvement in arterial stiffness might be helpful for a better prognosis in individuals with slightly reduced renal function, and our results highlight the role of arterial stiffness as a potential therapeutic target in individuals with mildly impaired renal function.

Another interesting finding of our study was that in individuals with eGFR $\geq 90 \mathrm{~mL} / \mathrm{min} / 1.73 \mathrm{~m}^{2}$, the risk of MACEs did not increase with incremental cf-PWV according to adjusted models (HR 1.398, 95\% CI 0.748-2.613; $P=0.293$ ). That is to say, the predictive value of arterial stiffness was limited in individuals with normal renal function. There may be many explanations for this result. Subclinical impairment might not have been observed or evaluated with the insufficient follow-up period, and thus the predictive value of increased arterial stiffness might have been affected to some extent.

\section{Study strengths}

To the best of our knowledge, the present investigation is the first study evaluating the association between arterial stiffness and MACEs in individuals with mild impaired renal function; therefore, it differs from those studies that focused on the predictive value of arterial stiffness on CVD only in 
advanced CKD. As such, active monitoring and treatment of arterial stiffness would be required to reduce the risk of MACEs in certain individuals.

\section{Study limitations}

The limitations of this study should also be taken into account. First, the present study was carried out only among the Chinese from a community in Beijing. Therefore, these results may not represent the Chinese population from other areas of the People's Republic of China and might not be applicable to other ethnic groups. Second, although the results were adjusted for multiple covariates, other residual confounding factors may remain.

\section{Conclusion}

The present community-based prospective study clearly demonstrated that arterial stiffness is a moderate and independent predictive factor for MACEs in individuals with mildly impaired renal function (eGFR $<90 \mathrm{~mL} / \mathrm{min} / 1.73 \mathrm{~m}^{2}$ ). Furthermore, in individuals with normal renal function (eGFR $\geq 90 \mathrm{~mL} / \mathrm{min} / 1.73 \mathrm{~m}^{2}$ ), the risk of MACEs does not increase with arterial stiffening.

\section{Acknowledgments}

We thank our colleagues in the Department of Laboratory Medicine at PLA General Hospital for help with biochemical measurements. We are also grateful to all study participants for their involvement in the study. This research was supported by a grant from the Key National Basic Research Program of China (2012CB517503, 2013CB530804) and the Key Science and Technology Foundation of China (2012ZX09303004-002) to PY.

\section{Disclosure}

The authors report no conflicts of interest in this work.

\section{References}

1. Kullo IJ, Malik AR. Arterial ultrasonography and tonometry as adjuncts to cardiovascular risk stratification. J Am Coll Cardiol. 2007;49: 1413-1426.

2. Vlachopoulos C, Aznaouridis K, Stefanadis C. Clinical appraisal of arterial stiffness: the Argonauts in front of the Golden Fleece. Heart. 2006; 92:1544-1550.

3. O'Rourke MF, Staessen JA, Vlachopoulos C, Duprez D, Plante GE. Clinical applications of arterial stiffness: definitions and reference values. Am J Hypertens. 2002;15:426-444.

4. McEniery C, Cockcroft JR. Does arterial stiffness predict atherosclerotic coronary events? Adv Cardiol. 2007;44:160-172.

5. Laurent S, Cockcroft J, Van Bortel L, et al. Expert consensus document on arterial stiffness: methodological issues and clinical applications. Eur Heart J. 2006;27:2588-2605.
6. Avolio AP, Chen SG, Wang RP, Zhang CL, Li MF, O'Rourke MF. Effects of aging on changing arterial compliance and left ventricular load in a northern Chinese urban community. Circulation. 1983;68: $50-58$.

7. Asmar R, Benetos A, Topouchian J, et al. Assessment of arterial distensibility by automatic pulse wave velocity measurement. Validation and clinical application study. Hypertension. 1995;26:485-490.

8. Keith DS, Nichols GA, Gullion CM, Brown JB, Smith DH. Longitudinal follow-up and outcomes among a population with chronic kidney disease in a large managed care organization. Arch Intern Med. 2004;164: 659-663.

9. Madero M, Peralta C, Katz R, et al. Association of arterial rigidity with incident kidney disease and kidney function decline: the health $\mathrm{ABC}$ study. Clin J Am Soc Nephrol. 2013;8:424-433.

10. Pannier B, Guérin AP, Marchais SJ, Métivier F, London GM. Arterial structure and function in end-stage renal disease. Artery Res. 2007;1: 79-88.

11. Blacher J, Guérin AP, Pannier B, Marchais SJ, Safar ME, London GM. Impact of aortic stiffness on survival in end-stage renal disease. Circulation. 1999;99:2434-2439.

12. Blacher J, Safar ME, Guérin AP, Pannier B, Marchais SJ, London GM. Aortic pulse wave velocity index and mortality in end-stage renal disease. Kidney Int. 2003;63:1852-1860.

13. Shoji T, Emoto M, Shinohara N, et al. Diabetes mellitus, aortic stiffness, and cardiovascular mortality in end-stage renal disease. J Am Soc Nephrol. 2001;12:2117-2124.

14. Van Biesen W, De Bacquer D, Verbeke F, Delanghe J, Lameire N, Vanholder R. The glomerular filtration rate in an apparently healthy population and its relation with cardiovascular mortality during 10 years. Eur Heart J. 2007;28:478-483.

15. Wang TJ, Gona P, Larson MG, et al. Multiple biomarkers for the prediction of first major cardiovascular events and death. $N$ Engl J Med. 2006;355:2631-2639.

16. Avolio AP, Van Bortel LM, Boutouyrie P, et al. Role of pulse pressure amplification in arterial hypertension: experts' opinion and review of the data. Hypertension. 2009;54:375-383.

17. Davies JE, Parker KH, Francis DP, Hughes AD, Mayet J. What is the role of the aorta in directing coronary blood flow? Heart. 2008;94: $1545-1547$.

18. O'Rourke MF, Safar ME. Relationship between aortic stiffening and microvascular disease in brain and kidney: cause and logic of therapy. Hypertension. 2005;46:200-204.

19. Chue CD, Townend JN, Steeds RP, Ferro CJ. Arterial stiffness in chronic kidney disease: causes and consequences. Heart. 2010;96:817-823.

20. Laurent S, Boutouyrie P, Asmar R, et al. Aortic stiffness is an independent predictor of all-cause and cardiovascular mortality in hypertensive patients. Hypertension. 2001;37:1236-1241.

21. Meaume S, Benetos A, Henry OF, Rudnichi A, Safar ME. Aortic pulse wave velocity predicts cardiovascular mortality in subjects $>70$ years of age. Arterioscler Thromb Vasc Biol. 2001;21:2046-2050.

22. Choi CU, Park EB, Suh SY, et al. Impact of aortic stiffness on cardiovascular disease in patients with chest pain. Assessment with direct intra-arterial measurement. Am J Hypertens. 2007;20:1163-1169.

23. Vlachopoulos C, Aznaouridis K, Stefanadis C. Prediction of cardiovascular events and all-cause mortality with arterial stiffness: a systematic review and meta-analysis. $J$ Am Coll Cardiol. 2010;55: $1318-1327$.

24. Go AS, Chertow GM, Fan D, McCulloch CE, Hsu CY. Chronic kidney disease and the risks of death, cardiovascular events, and hospitalization. N Engl J Med. 2004;351:1296-1305.

25. National Kidney Foundation. K/DOQI clinical practice guidelines for chronic kidney disease: evaluation, classification, and stratification. Am J Kidney Dis. 2002;39 Suppl 1:S1-S266.

26. Manjunath G, Tighiouart H, Ibrahim H, et al. Level of kidney function as a risk factor for atherosclerotic cardiovascular outcomes in the community. J Am Coll Cardiol. 2003;41:47-55. 
27. Blacher J, Guerin AP, Pannier B, Marchais SJ, Safar ME, London GM. Impact of aortic stiffness on survival in end-stage renal disease. Circulation. 1999;99:2434-2439.

28. Pannier B, Guérin AP, Marchais SJ, Safar ME, London GM. Stiffness of capacitive and conduit arteries: prognostic significance for end-stage renal disease patients. Hypertension. 2005;45:592-596.

29. Guérin AP, Blacher J, Pannier B, Marchais SJ, Safar ME, London GM. Impact of aortic stiffness attenuation on survival of patients in end-stage renal failure. Circulation. 2001;103:987-992.
30. Coresh J, Selvin E, Stevens LA, et al. Prevalence of chronic kidney disease in the United States. JAMA. 2007;298:2038-2047.

31. Baigent $\mathrm{C}$, Landray $\mathrm{M}$. Which cardiovascular risk factors matter in chronic kidney disease? Nephrol Dial Transplant. 2007;22:9-11.

32. Strippoli GF, Craig JC, Schena FP. The number, quality, and coverage of randomized controlled trials in nephrology. J Am Soc Nephrol. 2004; $15: 411-419$

\section{Publish your work in this journal}

Clinical Interventions in Aging is an international, peer-reviewed journal focusing on evidence-based reports on the value or lack thereof of treatments intended to prevent or delay the onset of maladaptive correlates of aging in human beings. This journal is indexed on PubMed Central, MedLine,

\section{Dovepress}

CAS, Scopus and the Elsevier Bibliographic databases. The manuscript management system is completely online and includes a very quick and fair peer-review system, which is all easy to use. Visit http://www.dovepress. $\mathrm{com} /$ testimonials.php to read real quotes from published authors. 